IBIMA Publishing

International Journal of Veterinary Medicine: Research \& Reports

http://www.ibimapublishing.com/journals/IJVMR/ijvmr.html

Vol. 2015 (2015), Article ID 709104, 8 pages

DOI: $10.5171 / 2015.709104$

Research Article

\title{
Ocular Field Surgery in Ruminants
}

\author{
Magda Mahmoud Ali ${ }^{1}$, Madeh Adel Sadan ${ }^{2}$ and Ahmed Ibrahim ${ }^{3}$ \\ 1,3 Faculty of Veterinary Medicine, Assiut University, Assiut, Egypt \\ ${ }^{2}$ Department of Surgery, Anesthesiology and Radiology. Faculty of Veterinary Medicine, South Valley \\ University, Egypt
}

Correspondence should be addressed to: Madeh Adel Sadan; madehsadan@vet.svu.edu.eg

Received date: 25 May 2015; Accepted date: 28 August 2015; Published date: 2 December 2015

Academic Editor: Murat Sevik

Copyright $\odot$ 2015. Magda Mahmoud Ali, Madeh Adel Sadan and Ahmed Ibrahim. Distributed under Creative Commons CC-BY 4.0

\begin{abstract}
Ocular disease and injury remain a common occurrence in ruminants. In many instances, medical management is sufficient. In selected cases, surgical intervention is required. Fortunately, field surgery remains a viable option for most cases of bovine ocular disease. Thorough physical examination, proper preparation of the patient, appropriate preoperative management, and good surgical technique will assure the best results possible. The present study aimed to describe different common types of surgical field ocular lesions in ruminant and their treatment, postoperative care and complications. 24 animals ( 1 goat, 4 buffaloes and 19 cattle ( 7 native and 12 Friesian)) were reported in this study suffering different ocular lesions such as: corneal foreign body, third eye lid and corneal Dermoid, Lens luxation, corneal ulcer, ocular tumor (squamous cell carcinoma), microphthalmia, purulent panophthalmitis and cataract. Surgical treatment was applied after thorough preoperative preparation. In twelve cases, the follow up reports showed improvement of animal health condition without postoperative complications.
\end{abstract}

Key words: Ocular, Surgery, buffalo, bovine.

\section{Introduction}

Ocular disease and injury remain a common occurrence in ruminants. In many instances, medical management is sufficient for the resolution and amelioration of clinical signs. In selected cases, surgical intervention is required (Irby, 2004). Although animals with many ophthalmic diseases may continue to eat and produce milk reasonably well, but they usually tend to lose weight (Rubin, 1984;
Rahman et al., 2012). As a result, they are condemned to slaughter especially in case of cancer eye which is by some estimates responsible for $12 \%$ of all carcass condemnation and are refused by auction markets (Ruggles et al., 1992; Samad, 2001). The presence of such many eye lesions in clear view on a dairy farm may lead the general public to question the humane treatment of animals on that farm and in the dairy industry in general (Hirsbrunner et al., 1998; Rahman et al., 2012). Fortunately, field surgery remains a

Cite this Article as: Magda Mahmoud Ali, Madeh Adel Sadan and Ahmed Ibrahim (2015), “Ocular Field Surgery in Ruminants," International Journal of Veterinary Medicine: Research \& Reportss,

Vol. 2015(2015), Article ID 709104, DOI: 10.5171/2015.709104 
viable option for most cases of bovine ocular disease. While the surgical techniques are not new, thorough physical examination, proper preparation of the patient, appropriate preoperative management and good surgical technique will assure the best results possible (Schulz and Anderson, 2010).

\section{Material and Methods}

\section{Animals}

24 ruminant animals were reported in this study, including ( 4 buffaloes, one goat, and 19 cattle ( 7 native and 12 Friesian)). All animals were adult and above five years old. 21 animals were females and only three animals were males.

\section{Clinical Symptoms}

The clinical symptoms varied according to the affection but some signs were reported in most of the cases including: marked pain when the eye is exposed to direct sun light. The ocular lesions were very painful and disrupt grazing patterns causing poor performance and even weight loss. Bilateral lesions cause temporary blindness and the affected animals tended to wander aimlessly about. Tear staining of the face, pus matting the lashes and hair of the face, severe conjunctivitis, superficial and deep vascularization of the cornea and corneal ulceration were the most common complications observed in the delayed treated cases.

\section{Anesthesia}

Xylazine premedication was used for all cases out of the goat case in a dose 0.02$0.20 \mathrm{mg} / \mathrm{kg}$ I.M. Examination of the eye was facilitated by reducing upper eyelid movement; therefore Auriculopalpebral nerve block was placed with an injection of 5 milliliters of $2 \%$ lidocaine $\mathrm{HCl}$ subcutaneously on the dorsal aspect of the zygomatic arch. Surgical manipulation of the eye was performed in conscious animals, under the effect of four Point retrobulbar nerve block using 2\% Lidocaine injected with an 18 gauge, 9-cm long needle which was introduced through the skin on the dorsal, lateral, ventral and medial aspects of the eye, at $12,3,6$, and 9 'clock positions, respectively (Ivany, 2004). Sub-conjunctival injection with eye drops of Lidocaine $2 \%$ were performed in one buffalo affected with a corneal foreign body.

\section{Pre-operative management}

\section{Anti-inflammatory/analgesic therapy}

The disease process and degree of invasiveness determined usually the degree of anti-inflammatory therapy required. Flunixin meglumine $(1 \mathrm{mg} / \mathrm{kg} \mathrm{IV})$ was immediately used before eye enucleation procedure which was performed in twelve of the examined cases (eleven cattle and one goat).

\section{Antibiotic therapy}

Broad spectrum systemic antibiotic therapy was required in all cases especially in those cases in which eye enucleation was performed.

\section{Surgical site preparation}

The hair around the eye was clipped and the skin was disinfected with betadine, the ear was draped and the lateral portion of the halter was covered to decrease contamination to the surgical site. Saline solution rinse was used rather than antiseptic scrubs to prevent irritation and damage to the cornea and an ophthalmic ointment was placed on the cornea prior to aseptic preparation to further protect the cornea from damage in cases other than enucleation.

\section{Surgical manipulation}

Surgical manipulation varied according to the animal health condition and severity of the condition.

- In one buffalo, which was suffering a corneal foreign body, the foreign body (wooden piece) was extracted through the entrance opening of the foreign body at the level of the limbus using a mosquito artery forceps. The wound was very small and was left opened. 
Enucleation was performed in twelve cases (eleven cattle and one goat) as following: the upper and lower eyelids were sutured together. A circumferential skin incision was made approximately one centimeter from the edges of the eyelids. Using a combination of blunt and sharp dissection, through the orbicularis oculi muscle, fascia, and subcutaneous tissue surrounding the eye. The interior of the bony orbit was used as a guide. The medial and lateral canthal ligaments were sharply transected to allow access to the caudal aspect of the orbit. The retrobulbar musculature and the optic nerve sheath were transected as far caudally as feasible. In four cases where neoplastic infiltration of the bony orbit has occurred, affected areas of ocular periosteum were thoroughly excised. Gauze packs or drains, or both, were temporarily placed in the orbit of all operated animals for the first 24 hours after operation. The skin incision was then closed in a simple interrupted suture patterns with No. 3 nylon, or Silk.

- Third eyelid dermoid in five cases was treated through total excision of its free end after applying an artery forceps close to the seat of incision and the wound was left opened. In the other case, the treatment was not possible where the dermoid was also attached to cornea.

\section{Post-operative care}

Animals were kept in a confined area for several days after surgery to allow appropriate hemostasis and healing to occur. Daily observation of the surgical site and assessment of general well being was performed until suture removal. Sutures were removed in 14 to 21 days to allow for complete healing of the skin.

\section{Results}

Table 1: Different ocular affections described in the study

\begin{tabular}{|c|c|c|c|c|}
\hline Ocular Lesion & Cattle & Buffalo & Goat & Treatment \\
\hline Lens luxation & 1 & 1 & - & None \\
\hline $\begin{array}{c}\text { Conjunctivitis } \\
\text { with corneal } \\
\text { ulcer }\end{array}$ & 3 & - & - & Enucleation \\
\hline $\begin{array}{c}\text { Squamous cell } \\
\text { carcinoma }\end{array}$ & 4 & - & - & Enucleation \\
\hline $\begin{array}{c}\text { Purulent } \\
\text { panothalmitis }\end{array}$ & 4 & - & - & Enucleation \\
\hline Foreign body & - & 1 & - & Removal \\
\hline Microphtalmia & 1 & 1 & - & None \\
\hline $\begin{array}{c}\text { Dermoid of } \\
\text { the 3rd eye lid }\end{array}$ & 5 & 1 & - & None \\
\hline Cataract & 1 & - & 1 & 24 \\
\hline Total & 19 & 4 & - & - \\
\hline
\end{tabular}

Of the 24 reported animals, there were no special breed or Gender more represented but all animals were above 5 years old. Cattle were more represented than other ruminants (19 animals) and females were more represented than males (21 Animals). In addition, most of the cases (15 animals) were admitted during the summer season due to hot weather which initiates the inflammatory process of the eye. Table (1) showed different cases admitted to the clinic with ocular lesions. Clinical diagnosis was based on results of physical examination and clinician professional judgment. The decision of treatment varied according to the animal's general health condition, type and extension of the lesion. Five cases were left without treatment; in one buffalo and one cattle suffering lens luxation, one cow suffering cataract, one cow and one buffalo suffering microphthalmia as no side effect 
from those lesions were observed on the animal health or production condition (figs. $1,2)$. In one buffalo, a corneal foreign body (wooden piece) was successfully extracted through the entrance opening; the wound was little and did not require suturing. The seat of the foreign body left superficial erosions on the cornea which disappeared spontaneously after one week without complications (figs. $3,4,5$ ).

In cases of dermoid of the third eyelid, no postoperative complications were recorded after resection of the free border of the third eyelid and the animal was able to return to graze normally within a week. In one case, the treatment was not possible where the dermoid was also attached to cornea and enucleation of the eye was not indicated (figs. 6, 7). In three cases suffering corneal ulcer with severe conjunctivitis and complications of corneal ulcer, medical treatment with antibiotic and application of third eye lid flap did not result in amelioration of clinical signs and enucleation was indicated (fig. 8). Enucleation was a successful treatment for different ocular lesions including: ocular tumors (4 cattle) (fig. 9), purulent panophthalmitis (4 cattle and one goat) (fig. 10), complicated cases of conjunctivitis and corneal ulcer (3 cattle). In addition, in

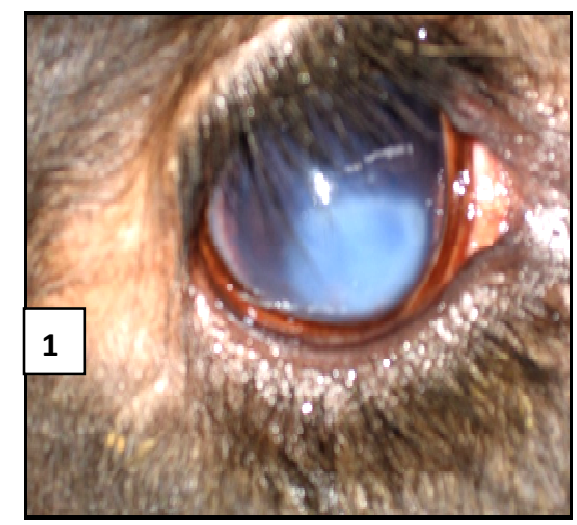

Figure 1: Lens luxation in a buffalo one case where dermoid of the $3^{\text {rd }}$ eye lid was attached also to the cornea was not possible to be resected. Intra-operative complications included hemorrhage in all cases of enucleation. However, no hemorrhage was severe enough to warrant supportive intervention outside of appropriate hemostasis measures such as ligation of the orbital artery, packing of the orbital cavity with gauze for 24 hours postoperatively, the use of hemostats, and suturing of the skin margins to form a seal. The most common postoperative complications recorded include simple incisional infection (2 cases), dehiscence of the suture due to pruritis and head rubbing after surgery which resulted in incisional dehiscence (3 cases). In 5 cases, purulent drainage was noted during the course of healing after the enucleation procedure. In these animals, the medial interrupted suture was removed and the orbital cavity flushed with a dilute antiseptic solution daily until resolution of the orbital infection. Antibiotic therapy was then recommended when systemic signs of infection were noted. Recurrence of tumor was not recorded in any of the cases during the first two months after treatment, but longtime follow up was not possible for any of the treated cases.

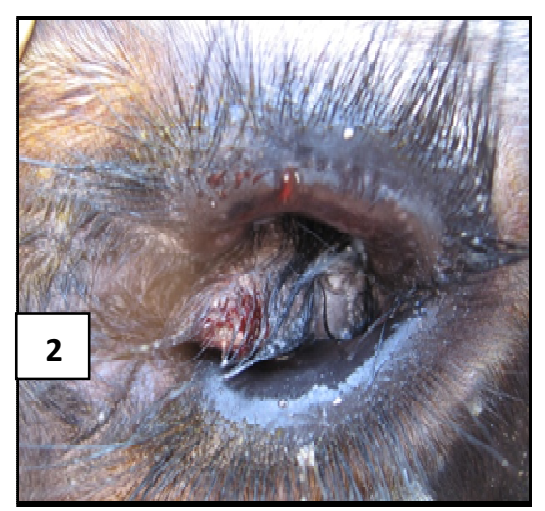

Figure 2: Microphtalmia with dermoid of the third eyelid in a cow 

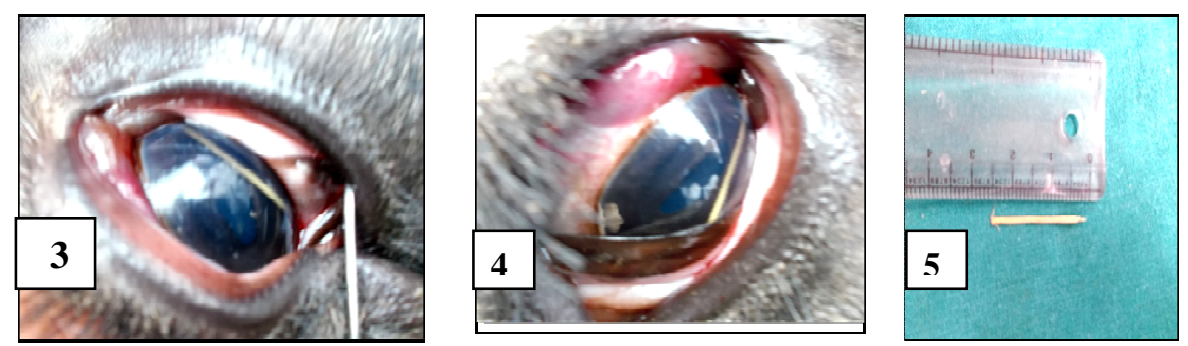

Figures 3, 4, 5: Corneal foreign body in a buffalo
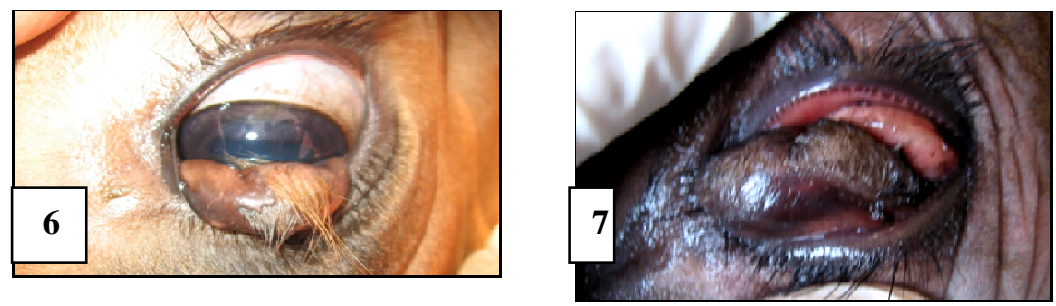

Figure 6, 7: Dermoid on the third eyelid and cornea in cow

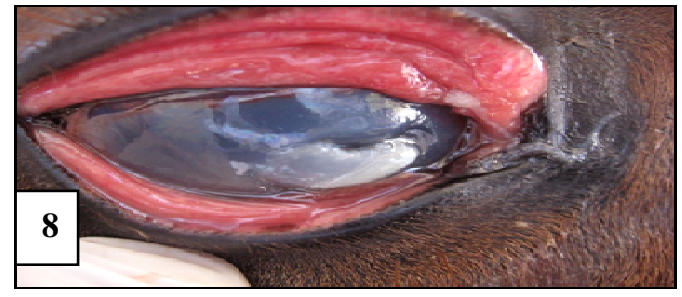

Figure 8: Corneal ulcer with conjunctivitis in a bull

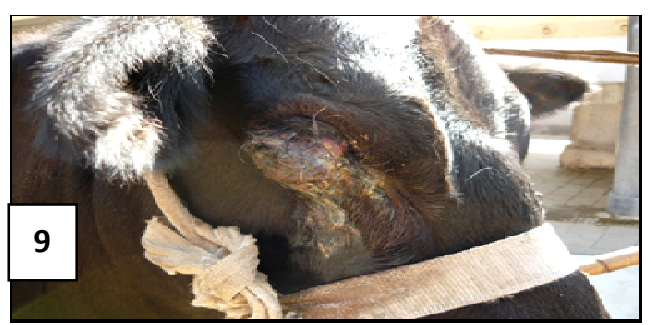

Figure 9: Squamous cell carcinoma in a cow

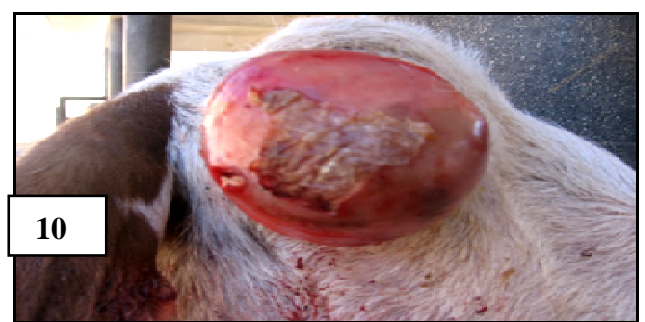

Figure 10: Panophthalmitis in a goat 


\section{Discussion}

This study describes most of the common ocular field lesions, and treatment for each condition. Most of the animals included in this study were cattle and most of the cattle were females. This predilection is likely due to the general population base of cowcalf ranches in the practice area but other authors referred this to a variety of factors, including not only the higher population of cattle but also the perceived cost-benefit ratio of treating a breeding cow as compared with a steer or a bull within a particular herd (Schulz and Anderson, 2010). However, the presence of more cattle than buffalo and small ruminant in our study could not be explained. But other authors recorded that eye diseases are higher in goat than cattle and in calves more than adults (Ruggles et al., 1992; Samad, 2001; Samad et al., 2002). In the present study, Friesian cattle was overrepresented than other, but in other studies Hereford cattle were overrepresented compared with the Angus breed cattle. This was likely due to the increased prevalence of ocular squamous cell carcinoma in Herefords, especially those lacking significant amounts of corneoscleral pigmentation (Ivany, 2004; Muir, 2005). But the occurrence of many cases in summer season was in agreement with previous studies (Samad et al., 2002).

In cattle, the course of therapy for severe ocular pathology is dictated not only by the disease entity present but also by the intended purpose and value of the animal as well as the cost, frequency, and efficacy of the chosen treatment (Vermunt, 1984). In our study, treatment of the ocular lesion varied according to the type and duration of the affection. However in some conditions where no side effects were observed, treatment was not performed. Ocular foreign body in buffalo was not reported before in any literatures described ocular pathology of ruminants. In our study, corneal foreign body (a wooden piece) was extracted in a buffalo without any complications except slight superficial erosions in the cornea, which healed completely after one week of treatment.

If the underlying disease allows for salvage of an eye with retention of vision, efforts should be made to preserve the eye if practical. In cases where salvage of the eye is not feasible, enucleation offers the potential for complete removal of diseased tissue and a rapid return to function (Schulz and Anderson, 2010). Enucleation is a common procedure in bovine practice but peer-reviewed literature regarding enucleation in cattle is scarce (Rubin, 1984; Samad, 2001; Samad et al., 2002; Irby, 2004; Schulz and Anderson, 2010; Rahman et al., 2012). Enucleation involves the removal of the globe with the removal of para-orbital structures as dictated by the specific disease process and desired outcome. In cattle, the ocular diseases encountered can be quite extensive or infiltrative, necessitating aggressive debridement of the para-orbital structures. This type of enucleation procedure is typically referred to as exenteration (Welker, 1995; Slatter, 2001; Irby, 2004). Indications for enucleation in our study included: massive purulent panophthalmitis, Ocular tumors, complicated cases of corneal ulceration and in one case the presence of dermoid on the cornea. Other indications for enucleation include chronic endophthalmitis or panophthalmitis leading to blindness in the affected eye, chronic glaucoma leading to buphthalmia and associated retinal and optic nerve damage, intraocular neoplasm where intraocular surgery is not feasible, trauma or proptosis of the globe leading to irreversible damage of the eye and intraocular contents (Bistner et al., 1977; Slatter, 2001; Schulz and Anderson, 2010). In our study, enucleation resolved a variety of ocular pathologies and allowed the animal to return to productive use at the herd of origin. The procedure was indicated for purulent panophthalmitis, ocular tumors (squamous cell carcinoma), complicated cases of corneal ulcer. In addition, the procedure was also indicated 
for one case of the third eyelid dermoid where the dermoid was extensive and was attached to the cornea.

All cases were treated under the effect of Xylazine tranquillizer associated with Lidocaine Hcl local anesthetic and all animals were kept conscious throughout the treatment procedure, however, no anesthetic complications were noted. Most of the clinicians elected the use of a retrobulbar nerve block for sensory and motor blockade of the orbit and surrounding tissues (Pearce, 2003; Schulz and Anderson, 2010). Other authors reported that there are several complications associated with local anesthesia. Retrobulbar anesthesia has been associated with orbital hemorrhage, penetration of the globe, optic nerve injury, and acute death following injection into the optic nerve meninges. Accidental injection of anesthetic into the ethmoid turbinates has been observed during performance of the Peterson eye block (Pearce, 2003). The only intraoperative complication causing concern in this study was hemorrhage in all cases of enucleation. However, no hemorrhage was severe enough to warrant supportive intervention outside of the appropriate hemostasis measures. Other complications associated with enucleation in animals include rupture of the globe during surgical manipulation with subsequent contamination of the surgical site, excessive orbital hemorrhage, excessive trauma to the remaining tissue leading to swelling or hemorrhage, discharge from the excision site due to an orbital infection, retained lacrimal duct or nictitans tissue, and peri-orbital cellulitis (Bistner et al., 1977; Schulz and Anderson, 2010). In our study, long term follow up was not possible due to loss of contact with the owner few time after surgery, therefore the recurrence of the ocular tumors was not observed. However, enucleation in our study was also indicated for other cases of eye lesions as massive ocular abscess with destruction of vital structures of the eye. However, ocular tumor recurrence after enucleation was not recorded even after long term follow up performed in other studies (Irby, 2004; Klein, 1984; Schulz and Anderson, 2010).

\section{Conclusion}

Enucleation remains a feasible, simple, inexpensive option of treatment for many types of severe ocular pathology. It has the potential to resolve chronic pain, infection, and neoplastic disease. Enucleation can be performed with routine restraint and surgical equipment at minimal cost to the client. Post-operative complications of the operative site are minimal. Retention within the herd is based largely on owner preference and the value of the animal.

\section{References}

1. Bistner, S., Aguirre, G. and Batik G. (1977) "Atlas of Veterinary Ophthalmic Surgery", Philadelphia: Saunders, Diseases of the orbit; pp. 245-278.

2. Hirsbrunner, G., Ebeid, M. and Eicher, R. (1998) " Cancer eye in cattle: 21 cases (1990-1996) , " Schweiz Arch Tierheilkd.140:149-155.

3. Irby, N.L. (2004) " Surgical Diseases of the Eye in Farm Animals. In: Farm Animal Surgery," Saunders, St. Louis, USA, Pp 429459.

4. Ivany, J.M. (2004) "Farm Animal Anesthesia. In: Fubini S, Ducharme NG (eds). Farm Animal Surgery," Saunders, St. Louis, USA, Pp. 97- 112.

5. Klein, W.R, Bier, J. and Dieten, J.S. (1984)"Radical surgery of bovine ocular squamous cell carcinoma (cancer eye): Complications and results," Vet Surg., 13:236-242.

6. Muir, M.W. (2005) "Local Anesthesia in Ruminants and Pigs. In: Handbook of Veterinary Anesthesia," $4^{\text {th }}$ ed. Mosby, St. Louis, USA, Pp. 72-99.

7. Pearce, S.G., Kerr, C.L. and Boure, L.P. (2003) "Comparison of the retrobulbar and Peterson nerve block techniques via magnetic resonance imaging in bovine cadavers," J Am Vet Med Assoc., 223:852855. 
8. Rahman, M.A., Islam, M.A., Talukder, A.K., Parvin, M.S. and Islam M.T. (2012) "Clinical diseases of ruminants recorded at the Patuakhali science and technology University veterinary clinic," Bang. J. Vet. Med. 10 (1\&2): 63-73.

9. Rubin, L.F. (1984) "Large Animal Ophthalmic Surgery," In: The Practice of Large Animal Surgery, Vol. II. Saunders, Philadelphia, USA, Pp1151-1201.

10. Ruggles, A.J., Irby, N.L., and Saik, J.E. (1992) "Ocular lymphangio-sarcoma in a cow," J Am Vet Med Assoc., 200:19871988.

11. Samad, M.A. (2001) "Observations of clinical diseases in ruminants at the Bangladesh Agricultural University," Veterinary Clinic. Bangladesh Veterinary Journal 35: 93-120.
12. Samad, M.A., Islam, M.A. and Hossain, A. (2002) "Patterns of occurrence of calf diseases in the district of Mymensingh in Bangladesh,". Bangladesh Veterinary Journal 36: 01-05.

13. Schulz, K.L. and Anderson D.E. (2010) "Bovine enucleation: A retrospective study of 53 cases (1998-2006) ," Can Vet J. Jun; 51(6): 611-614.

14. Slatter, D. (2001) "Fundamentals of Veterinary Ophthalmology,".3rd ed. Philadelphia: WB Saunders, Orbit; pp. 496531.

15. Vermunt, J. (1984) "Transpalpebral exenteration in cattle," Vet Q. 6:46-48.

16. Welker B. (1995). "Ocular Surgery,". Vet Clin North Am Food An Pract.; 11:149-157. 